\title{
Horacio Quiroga e Leopoldo Lugones: interfaces do fantástico
}

\author{
Carolina dos Santos Carboni*
}

\begin{abstract}
Resumo: Horacio Quiroga e Leopoldo Lugones são pouco conhecidos nos estudos de literatura hispanoamericana desenvolvidos no Brasil. Hoje em dia suas obras chamam atenção no cenário latino-americano, principalmente pelo gênero fantástico que exploraram em suas narrativas e que os tornaram célebres. Nos contos "El almohadón de plumas" e "El escuerzo", os autores uruguaio e argentino, respectivamente, se valem do fantástico para retratar temáticas próximas. Este artigo pretende fazer um estudo comparativo desses dois contos utilizando as perspectivas da Literatura Comparada.
\end{abstract}

Palavras-chave: Fantástico; Quiroga; Lugones; Conto

\begin{abstract}
Horacio Quiroga and Leopoldo Lugones are not widely known in the studies of Hispanic American Literature developed in Brazil. Nowadays their works have been calling attention in the LatinAmerican scenery mainly because of the fantastic genre that they explore in theirs narratives which made them celebrated. In the short stories "El almohadón de plumas" and "El escuerzo" both authors, the Uruguayan and the Argentinean, use the fantastic to picture similar themes. This paper intends to do a comparative study of these two short stories using the Comparative Literature perspectives.
\end{abstract}

Keywords: Fantastic; Quiroga; Lugones; Short story; Comparative Literature

Escribo siempre que puedo, con náuseas al comenzar y satisfacción al concluir.

Horacio Quiroga

Horacio Quiroga e Leopoldo Lugones são autores de grande prestígio no âmbito da literatura hispano-americana. Pode-se observar, no entanto, que no Brasil há pouca pesquisa sobre a produção dos países americanos de língua espanhola, fato não propício ao desenvolvimento da área.

Lugones (1874 - 1938), argentino, teve uma atividade jornalística intensa durante toda a vida. Foi um dos modernistas mais representativos da Argentina. Produziu textos literários de vários gêneros, como narrativa, poesia e ensaio e, inclusive, em outras áreas do conhecimento, como as ciências exatas e o ocultismo. Foi o responsável pela renovação literária na Argentina, um discípulo de Rubén Darío e do modernismo europeu. Assim, influenciou escritores como Quiroga e fez escola. Foi muito ativo politicamente. Durante sua vida foi partidário primeiro do socialismo, mudando depois para a democracia e, por último, para o nacionalismo fascista e xenófobo. Em sua obra o que mais se destaca é a narrativa e a

\footnotetext{
* Tradutora, graduada em Letras Bacharelado Português/Espanhol pela Universidade Federal do Rio Grande do Sul em 2008. E-mail: carolina.carboni@gmail.com
} 
poesia. Quanto àquela, foi grande representante da contística fantástica, sendo até um dos mais lembrados escritores do gênero no cenário hispano-americano.

Quiroga (1878 - 1937), uruguaio, recebeu direta influência do Modernismo que passava a produzir efeitos sobre os escritores jovens da época. Lugones figura constante na sua vida, também exerceu parte dessa influência sobre as suas preferências e a busca da sua própria identidade e personalidade. Em 1900, o autor de Cuentos de amor, de locura y de muerte viaja a Paris onde permanece por quatro meses. Quando regressa, nutrido pelas idéias de Rubén Darío, funda o "Consistorio do Gay Saber", círculo de estudos entre amigos literatos para discussão do Modernismo.

Depois de uma viagem que faz junto a Lugones para Misiones, interior da Argentina, em 1903, a vida de Quiroga não seria mais a mesma. Aconselhado por Lugones, o escritor uruguaio, na tentativa de encontrar-se, muda de residência e de estilo de vida. Em meio à euforia, resultado do contato que travara com as novas tendências estéticas, e ao sentimento de incompletude, Quiroga procura na vida campestre a razão e o autoentendimento. Logo, a mudança de estilo também se dá na sua produção literária, da narrativa modernista para temas relacionados com a selva. Uma busca de si mesmo.

Quiroga foi fértil na narrativa, sendo o conto o gênero que usou como pilar para expressar suas inquietações e medos. Através do conto fantástico deixou uma rica herança para a literatura hispano-americana. Como temática dominante, a morte é elemento sempre presente no conto quiroguiano. Pode-se dividir o tema em dois momentos dentro de sua obra: a morte por acaso - acidentes, imprevistos - e a induzida - o homem nega a própria vida consequência do meio e da própria impotência diante das circunstâncias.

\section{Do fantástico}

A literatura do final do século XIX e início do XX foi muito profícua na produção da narrativa fantástica, e o conto era a forma ideal para muitos escritores em todo o planeta. No âmbito do continente americano fez-se muito rica essa produção, transformando tal literatura em referência mundial. Tanto os norte-americanos quanto os latino-americanos produziram contos fantásticos que marcaram estilo e deixaram seguidores ao longo do século XX. Dos mestres como Edgar Allan Poe e Lovecraft se herdou metodologias para a produção, fato que influenciou os escritos de Horacio Quiroga e Leopoldo Lugones.

Os contos de Quiroga e Lugones são reconhecidos como de grande qualidade. Quando se pensa em literatura fantástica latino-americana logo vem à mente o nome do autor 
uruguaio, porém o argentino, no Brasil, pode-se dizer que é pouco conhecido. Lugones, na Argentina, é referência nacional; parece, porém, que não conseguiu ultrapassar as fronteiras de seu país, pelo menos é o que parece no Brasil.

Os dois autores hispano-americanos apresentam uma contística fantástica muito semelhante, principalmente no que concerne aos temas por eles abordados. Exatamente neste ponto reside a justificativa para este estudo.

O fantástico é um gênero cuja especificidade ainda não se chegou a um acordo nos dias de hoje. Uma definição genérica para o que é fantástico é apresentada por Todorov: "O fantástico é a hesitação experimentada por um ser que só conhece as leis naturais, face a um acontecimento aparentemente sobrenatural" (TODOROV, 2004, p. 31). O autor acrescenta mais adiante que a hesitação seria apenas uma das características definidoras do fantástico.

Todorov afirma que não se pode definir o fantástico como um gênero, senão como um momento dentro da narrativa, existente somente por um período de tempo curto. $\mathrm{O}$ fantástico não perdura, se desvanece, não é algo que se possa afirmar como fixo. Por isso, a debilidade em se dizer que é um gênero da mesma forma como, por exemplo, o "estranho" e o "maravilhoso" são gêneros.

Segundo Todorov (2004), não se pode definir o fantástico como gênero literário, uma vez que este se encontraria na área de divisa entre o estranho e o maravilhoso. O estranho seria o sobrenatural explicado, ou seja, que apresenta uma explicação racional para o fato que provoca a hesitação em relação ao sobrenatural na narrativa. Já o maravilhoso seria o sobrenatural aceito, aquele que é visto como natural dentro do universo da narrativa.

O teórico russo aponta que para a existência do fantástico é necessária a presença de algumas condições básicas. A primeira é que o leitor tem que sentir o ambiente do texto como real para o mundo das personagens. Mesmo que seja algo irreal no mundo real, tem que passar a idéia de normalidade no mundo de dentro da narrativa. Depois, o leitor tem que sentir a hesitação postulada por Todorov sobre o acontecimento que está em jogo no texto. A segunda condição se refere à hesitação da personagem: se a personagem vivencia a hesitação que o leitor sente é um ganho para a plenitude do fantástico. Isso não é obrigatório nas narrativas do tipo; se acontecer, porém, é por que o leitor realmente se identifica com a personagem. A terceira condição retrata a atmosfera negativa: não basta a ocorrência de um fato que possa parecer sobrenatural. As obras alegóricas e as poéticas também podem retratar esses acontecimentos, mas a presença do fantástico como fenômeno dubitável e que causa medo e terror necessita de uma implicação de caráter negativo. 
Essas seriam as leis "gerais" para a definição do fantástico.

Adolfo Bioy Casares, em sua Antología de la literatura fantástica (2007), organizada juntamente com Jorge Luis Borges e Silvina Ocampo, diz ser o fantástico um "gênero mais ou menos definido". Vários teóricos tentaram prescrever leis que identifiquem o conto fantástico. O escritor argentino, porém, diz não existir uma só, senão várias. Postula que existem leis gerais e leis especiais e que cabe ao contista perguntar-se quais nortearão a escrita de seu conto. Logo, o seu fazer pode ser resolvido parte pelas leis gerais e pré-estabelecidas e parte por leis especiais. Cabe a ele descobri-las e escolher quais seguirá (cf. BIOY CASARES, 2007, p. 8).

É nessa visão de fantástico que se encaixam os contos de Quiroga e Lugones. O teórico argentino diverge parcialmente da visão do russo, propiciando mais facetas ao fantástico praticado na América Latina. As leis gerais seriam as leis tradicionais estudadas justamente por Todorov. As leis especiais seriam as que fogem dessa perspectiva, dando margem a novos tipos de narrativas fantásticas, novas visões representadas principalmente na América do Sul. Elas não poderiam ser definidas hermeticamente como fez o teórico russo, por isso são tidas como especiais. Os relatos fantásticos, ao longo do século XX, vão adquirindo novas formas de atuarem. É nesse âmbito que se insere a obra dos escritores rioplatenses. Suas narrativas atingem uma nova faceta do fantástico, se caracterizando pela cor local dos hispano-americanos. Dada tal qualificação, categoriza-se que os contos dos autores não apresentam a "hesitação" que Todorov argumenta, porém se encaixam nas outras diretrizes defendidas pelo russo e apresentam novos aspectos e estilos.

\section{Os contos}

"El escuerzo" é o relato de alguém sobre um fato singular que ocorreu durante a sua infância. Foi escrito em primeira pessoa e possui uma espécie de subdivisão temporal e espacial. O narrador, quando menino, mata um sapo a pedradas, como de praxe nas brincadeiras das crianças que crescem em contato com a vida campestre. Parecendo-lhe o animal um pouco diferente dos que habitualmente encontrava no campo, o rapazinho leva o sapo para que uma criada de sua casa lhe explique que espécie seria.

A problemática do conto começa quando a criada adverte o menino de que havia matado um animal que "ressuscita para vingar-se". Se eles não queimassem imediatamente o corpo do anfíbio, as consequências seriam trágicas. Para explicar o resultado da morte do animal e, ao mesmo tempo, advertir do mal que estava por vir, a criada narra ao menino a 
história de Antonia, uma finada amiga sua que vivenciou um caso semelhante e que resultou em uma tragédia, consequência da morte de um escuerzo. Nesse segundo momento do conto, os fatos ocorrem ao contrário do primeiro momento. As personagens não conseguem se deslindar da ameaça exercida pelo sapo, sofrendo assim a pena da violação da lei desse universo.

"El almohadón de plumas" narra a história de um jovem casal. Alicia, a esposa, passa a sofrer de uma enfermidade da qual os médicos não conseguem curar. A doença evolui rapidamente até levá-la à morte. Durante o tempo de evolução da enfermidade, ninguém desconfia que a causa da morte de Alicia tinha um fator externo: dentro de seu travesseiro, a empregada e o marido encontram uma criatura bizarra e horrenda: um parasita de aves que, segundo o narrador, é comumente encontrado dentro de travesseiros. Tal animal, durante todo o tempo de evolução da doença, sugara o sangue de Alicia, sem que ninguém se desse conta disso, até tirar sua vida.

As personagens principais dos dois contos possuem algumas características em comum. O protagonista de "El Escuerzo", o próprio narrador, não revela seu nome em nenhum momento da narrativa. Por causa do pouco espaço de atuação dessa personagem dentro da história, o leitor fica em déficit quanto a mais detalhes para que possa ter uma visualização mais apurada do narrador-personagem. É possível, entretanto, extrair características que deixam pistas importantes para este estudo.

No conto, sabe-se que houve decorrência do tempo entre o momento da escrita do conto e o fato que será narrado. O pretérito imperfeito utilizado no parágrafo introdutório do conto faz a marcação: "Un día de tantos, jugando en la quinta de la casa donde habitaba la familia, di con un pequeño sapo [...]. Horrorizábanme los sapos y era mi diversión aplastar cuantos podía”. (LUGONES, 1987, p. 103, grifo nosso). Nota-se também o momento em que o próprio narrador cita que tinha oito anos de idade: "Tenía yo ocho años y ella sesenta" (LUGONES, 1987, p. 104). Esta é, porém, a única informação direta que nos dá como indício de tempo passado.

A personagem do conto "El almohadón de plumas" também nos é apresentada como jovem. "Su luna de miel fue un largo escalofrío. Rubia, angelical y tímida, el carácter duro de su marido heló sus soñadas niñerías de novia”. (QUIROGA, 2003, p. 62). Horacio Quiroga viveu entre 1879 e 1937, época em que era comum que as mulheres se casassem muito jovens. Aliado ao fato de que o narrador já nos dá indício da candura de Alicia: usa adjetivos associados à cor branca para a descrição de sua heroína. 
Aliado à característica da juventude de ambas as personagens está a inocência que demonstram possuir. O menino do conto de Lugones está acostumado a conviver em um meio onde a existência de anfíbios e répteis como sapos e lagartos é constante. Ele mesmo afirma em sua narrativa ser um sábio em se tratando desses animais. Dá-se conta, no entanto, de que o sapo que acaba de matar é diferente dos demais que está acostumado a encontrar. Logo, para buscar entendimento acerca do raro animal, vai à procura de uma pessoa mais experiente, no caso, a criada de sua casa, que é sua confidente de outras empreitadas de caça aos pequenos anfíbios e lagartos. O menino não tem condições de entender por si só a situação nova com a qual se depara.

No conto de Quiroga, Alicia sonhava com um casamento que não é o que a vida real lhe reserva. Ela tem uma visão idealizada de como seria seu casamento, como em um conto de fadas. Isso confere à personagem uma aura de inocência. Inocência também presente no narrador-personagem do conto de Lugones.

Em "El escuerzo" o narrador introduz a história contando um fato que ocorreu no passado, quando ele tinha oito anos de idade. O conto, no entanto, apresenta uma divisão do relato em dois momentos. O primeiro é a narração do protagonista sobre uma recordação sua de infância. A partir desse relato, o narrador constrói uma ponte com o segundo momento do conto. O primeiro se faz necessário como peça introdutória do segundo, pois é nesse trecho do conto que o narrador insere um acontecimento, a problemática, que, por sua vez, será desenvolvida somente no segundo momento.

A segunda parte passa a ser narrada em terceira pessoa e se trata de uma experiência não vivida pelo narrador da parte inicial. A história contada na segunda parte do texto é o relato da criada, personagem coadjuvante da primeira parte. Seu relato, porém, não é narrado pela sua própria voz, mas pela do narrador-protagonista do conto. Ele narra o relato da criada, um episódio da mesma natureza ao que fora vivenciado pelo narrador. Dessa vez, entretanto, sucedido com o filho de uma amiga, em algum momento no passado.

A segunda dá continuidade ao fato ocorrido na primeira, sendo a explicação e a razão da existência da mesma. É essa narrativa encaixada que provoca o impacto no leitor.

A estrutura de "El almohadón de plumas" difere de "El escuerzo". Naquela, Quiroga teve preferência pela narração uniforme, sem divisões temporais e de atuação de suas personagens. Ele constrói seu conto totalmente narrado em terceira pessoa. Em Lugones, sabíamos que o relato é a experiência de vida de alguém que decide contá-la. Já em Quiroga, não se pode dizer o mesmo, não há uma testemunha que dê ao leitor uma possível prova da existência do fato relatado. 
Os modos como os dois autores escrevem seus contos caracterizam suas formas de construir a atmosfera propícia para o relato de um acontecimento fantástico. O jogo do narrador que Lugones constrói em "El escuerzo" serve para conferir verossimilhança ao acontecimento sobrenatural narrado. É dessa forma que ele aproveita para apresentar o seu elemento desencadeador do desequilíbrio do ambiente e da crença das personagens, e, logo, afetar o leitor, seu alvo principal. A problemática lançada se baseia em um animal visto na natureza como inofensivo para um ser humano, seu predador. Os sapos, porém, possuem uma aparência física muitas vezes grotesca, além de terem uma forma fisiológica de defesa cujo mecanismo consiste em inchar-se para assustar e espantar o seu ameaçador. Para o ser humano não é uma ameaça letal. Lugones, entretanto, se aproveita dessa natureza dos sapos para recriar e construir uma história fantástica, resgatando mitos e medos do imaginário popular e materializando-os em sua narrativa. Tanto Lugones quanto Quiroga exploram características presentes em elementos que podem adquirir um status ameaçador. Ambos se valem de animais para criar um espaço atópico, adverso.

Quiroga, em seu "El almohadón de plumas", utiliza um animal que não conseguimos reconhecer a princípio: “[...] sobre el fondo, entre las plumas, moviendo lentamente las patas velludas, había un animal monstruoso, una bola viviente y viscosa. Estaba tan hinchado que apenas se le pronunciaba la boca" (QUIROGA, 2003, p. 65). O autor o descreve de maneira assustadora, parece que não possui nem cabeça, nem pernas, um ser disforme e difícil de recriar nos nossos pensamentos, justamente porque foge do padrão do considerado natural pelo ser humano. O belo causa deleite, já o feio, aversão. Sendo desconhecido, torna-se enigmático, podendo evoluir, conforme o caso do conto, para algo receoso. $\mathrm{O}$ desconhecido causa medo e intimida.

A partir da materialização do elemento chave para o desencadeamento da trama e evolução narrativa, Lugones arquiteta o ambiente onde tudo acontecerá em "El escuerzo". A composição com os elementos necessários é minuciosamente exposta. É a formulação da tensão, da intensidade do conto, desde a primeira frase. Conforme definiu Cortázar em seu ensaio Algunos aspectos del cuento:

\footnotetext{
El cuentista sabe que no puede proceder acumulativamente, que no tiene por aliado al tiempo; su único recurso es trabajar en profundidad, verticalmente, sea hacia arriba o hacia abajo del espacio literario [...]. El tiempo del cuento y el espacio del cuento tienen que estar como condenados, sometidos a una alta presión espiritual y formal para provocar esa "apertura" a que me refería antes. [...] podemos adelantar ya que las nociones de significación, de intensidad y de tensión han de permitirnos, como se verá, acercarnos mejor a la estructura misma del cuento. (CORTÁZAR, 1971, p. 407)
} 
O contista sabe que deve utilizar somente o essencial para montar a cena em que tudo ocorrerá. Essa abertura que menciona em seu ensaio se refere à comparação que preferiu usar para explanar a teoria do que é o conto para o contista. O conto é como uma fotografia, não há tempo para desenvolver elementos que façam parte no desenvolvimento imediato da problemática que o contista quer relatar em seu breve texto. Uma fotografia apresenta somente a imagem dos elementos que seu fotógrafo quis retratar. É estática, não possui evolução por meio de animação. Nela, entretanto, se pode ver tudo de uma vez só, todo o essencial está ali, somente é necessária a observação de quem a olha, sensibilidade para perceber coisas não expostas em primeiro plano, dentro do foco, da lente da máquina: as coisas que estão em segundo plano.

Assim são os dois contos. Se buscarmos as duas "fotografias", "El escuerzo" e "El almohadón de plumas", veremos na primeira, por exemplo, fundamentalmente duas pessoas, uma delas horrorizada e um "fantasma" de um sapo. Há pouca luz, a da lua, uma pequena casa campestre, a porta do quarto de uma das duas pessoas, e só. Já na segunda, vemos uma casa muito grande, muito iluminada e silenciosa, como um hospital, um casal jovem, cuja esposa está doente. A fisionomia deles é muito preocupante. Percebe-se que estão com problemas sérios. Há também o travesseiro onde a esposa dormira apoiada, e dentro dele há um animal estranho e monstruoso. Quem está segurando essa fotografia pode se aperceber de que a criatura foi a causadora do sofrimento do casal. A fisionomia do marido é de quem está horrorizado: a esposa fora assassinada pela criatura.

No parágrafo anterior, foram explanados os elementos principais das duas tramas. Podemos dizer que o exposto é o resumo dos contos, que contém as peças fundamentais para a montagem da trama. O conto funciona assim, sua estrutura é básica, contém somente os alicerces da construção, sem decoração supérflua. Ter uma estrutura básica não quer dizer que seja pobre. Ao contrário, é nessa simplicidade que o contista ganha por knock-out:

[...] en la medida en que la novela acumula progresivamente sus efectos en el lector, mientras que un buen cuento es incisivo, mordiente, sin cuartel desde las primeras frases. No se entienda esto demasiado literalmente, porque el buen cuentista es un boxeador muy astuto, y muchos de sus golpes iniciales pueden parecer poco eficaces cuando, en realidad, están minando ya las resistencias más sólidas del adversario. (CORTÁZAR, 1971, p. 406-407)

Cada frase é calculada, pois o contista não dispõe de espaço nem de tempo.

Atenhamo-nos, agora, à análise propriamente dita dos cenários construídos nos dois contos. Em "El escuerzo" há uma casa pequena, localizada no interior de um país não mencionado. É o que se pode deduzir: "Como todos los muchachos criados en la vida semicampestre de nuestras ciudades de provincia, yo era un sabio en lagartos y sapos" 
(LUGONES, 1987, p. 103). Há a presença de animais campestres, em que se inclui o animal desencadeador da problemática. A parte inicial do conto, na qual o narrador é o protagonista, se passa durante o dia, com a luz natural. No entanto, essa não é a cena principal. A segunda parte desenvolve a problemática real do conto, que reside na narração do caso de Antonia, finada amiga da criada da primeira parte da história. $\mathrm{O}$ ambiente começa iluminado com a luz natural do dia - quando ocorre a morte do sapo misterioso - e depois passa a escurecer conforme o dia vai findando. Tal fato também instiga a evolução do medo de Antonia, a mãe atônita que pressente a morte do filho através do castigo do animal vingativo. Conforme escurece o dia, aumenta o mistério e se aproxima o momento da volta do sapo. Dessa forma, intensifica-se a tensão do relato. Lugones desenvolve a intensidade até chegar ao clímax, a chegada da meia-noite e a aparição do sobrenatural: "Calculaba ella que sería la medianoche, pues la luna muy baja empezaba a bañar con su luz el aposento, cuando de repente un bultito negro, casi imperceptible, saltó sobre el dintel de la puerta que no se había cerrado por efecto del gran calor" (LUGONES, 1987, p. 107).

A casa também é mostrada com muita penumbra internamente. Em nenhum momento se menciona que estava iluminada, somente se cita que as duas personagens comeram no pátio sob a luz da lua. Mais adiante, também, quando o filho dorme enquanto a mãe vela o seu sono, sempre com a presença da luz da lua e nada de luzes artificiais: uma imagem propícia para a atmosfera de mistério e a aparição do sobrenatural. Ao se fazer um balanço sobre a presença da luz e da escuridão nesse conto percebe-se que a noite prevalece perante o dia. A noite estimula o mistério e agrava a situação de medo. $\mathrm{O}$ clímax está justamente na meianoite.

Passando à análise do cenário de "El Almohadón de plumas", vê-se uma casa grande, quase um palácio, sem mencionar se é interior ou cidade grande. Em nenhum momento se cita a participação de animais, à exceção do final, quando é revelada a chave do mistério. $\mathrm{O}$ elemento do cenário que está presente sempre em toda a narrativa é a luz, mas dessa vez luz artificial, associada à brancura dos objetos, à frieza e ao silêncio. A luz intensa participa de todo o conto, assim como elementos relacionados à "luz/branco", "silêncio":

La casa en que vivían influía un poco en sus estremecimientos. La blancura del patio silencioso - frisos, columnas y estatuas de mármol - producía una otoñal impresión de palacio encantado. Dentro, el brillo glacial del estuco, sin el más leve rasguño en las altas paredes, afirmaba aquella sensación de desapacible frío. Al cruzar de una pieza a otra, los pasos hallaban eco en toda la casa, como si un largo abandono hubiera sensibilizado su resonancia. En ese extraño nido de amor, Alicia pasó todo el otoño. No obstante, había concluido por echar un velo sobre sus antiguos sueños, y aún vivía dormida en la casa hostil, sin querer pensar en nada hasta que llegaba su marido. (QUIROGA, 2003, p. 62) 
A casa remete ao ambiente de um hospital, sempre muito silenciosa, com movimentação somente das pessoas que servem à doente. Alicia está enferma, apenas se vê a presença de seu marido e dos empregados. Tudo é frio, ligado ao fato da doença terminal e sem explicação. Todas essas características são opostas às utilizadas em "El escuerzo", porém a ausência de cores escuras reveladoras de mistério não faz falta na trama de Quiroga. Aqui, o branco é essencial para dar o efeito desejado, de doença inexplicável perante a medicina e o dia-a-dia de pessoas comuns como todos nós. É isso que ele tenta passar ao leitor, a normalidade e a naturalidade, o contrário de Lugones, que em seu texto nos mostra um caso típico de contos de cidades do interior e de pessoas simples. Para o texto de Quiroga, a estranheza surge a partir da normalidade. É como se ninguém estivesse livre da aparição inexplicável da morte em qualquer momento da vida, sendo o mais inesperado, inclusive. $\mathrm{O}$ singular nasce do trivial. Logo, pode-se dizer que esse conto está mais próximo a nós que o de Lugones, justamente por abordar um fato e ter como plano de fundo uma situação muito mais próxima à nossa vida real. $\mathrm{O}$ de Lugones suscita mais mistério e coisas que ocorrem somente nos momentos à parte de nosso cotidiano. É como as histórias que nossos avós nos contavam, quando éramos criança, antes de dormir. Algo feito para assustar e que povoa o nosso inconsciente.

O sobrenatural mora, em "El Almohadón de plumas", no fechamento da história. Depois do desenvolvimento de um caso possível e não incomum dentro das perspectivas de vida de um ser humano, surge a revelação do mistério. $\mathrm{O}$ ser humano sempre conviveu ao longo de sua existência com doenças terminais cuja causa fora inexplicável para a medicina. Até aqui vigora a normalidade. O leitor, até os últimos momentos do conto, espera para saber a causa da morte de Alicia. A partir desse momento, começa o fantástico e o antinatural. Se não fosse pelo título, não haveria a reserva que Quiroga propôs ao leitor em esperar, em interrogar-se sobre o objeto anunciado já no título: "El almohadón de plumas"1. O que há no travesseiro? O causador do desequilíbrio, uma criatura cuja descrição foge aos padrões do belo aos olhos humanos. A revelação do animal resulta na surpresa tanto das personagens quanto do leitor.

Tudo parecia correr dentro do curso habitual das vidas do casal, até que, sem que se esperasse, marido e mulher são surpreendidos por um fato não planejado. $\mathrm{O}$ autor nos demonstra que a vida pode nos surpreender e que contra isso não se pode lutar.

\footnotetext{
1 “O travesseiro de penas" (tradução nossa).
} 
Por último, falaremos do tempo nas narrativas. O escritor e teórico norte-americano Lovecraft postulou sobre a peculiaridade do tempo nos relatos fantásticos. O medo sempre foi constante na vida do ser humano e, associado ao jogo do tempo, resulta potencializada a presença da inquietação que o protagonista e o leitor ${ }^{2}$ sentem dentro e fora da narrativa fantástica. O escritor escreveu sobre seus contos fantásticos:

[...] uno de mis anhelos más fuertes es el de lograr la suspensión o violación momentánea de las irritantes limitaciones del tiempo [...] Estos cuentos tratan de incrementar la sensación de miedo, ya que el miedo es nuestra más fuerte y profunda emoción y una de las que mejor se presta a desafiar los cánones de las leyes naturales. El terror y lo desconocido están siempre relacionados, tan íntimamente unidos que es difícil crear una imagen convincente de la destrucción de las leyes naturales, de la alienación cósmica y de las presencias exteriores sin hacer énfasis en el sentimiento de miedo y horror. La razón por la cual el factor tiempo juega un papel tan importante en muchos de mis cuentos es debida a que es un elemento que vive en mi cerebro y al que considero como la cosa más profunda, dramática y terrible del universo. El conflicto con el tiempo es el tema más poderoso y prolífico de toda expresión humana. (LOVECRAFT, 2008, p. web)

O fator tempo aliado ao medo são os elementos chave dos contos de Lovecraft. Entretanto, também podemos associá-los nos contos dos dois escritores rio-platenses. Em "El escuerzo", o tempo é algo a ser vencido para que se mantenha o equilíbrio das vidas das personagens que rompem a lei da natureza. Para que o ser humano vença o animal sobrenatural, necessita queimar o corpo do sapo vingativo, mas para consegui-lo, precisa correr contra o tempo. Na narrativa não se menciona diretamente, mas a chegada da noite, sempre associada ao mistério, é o aviso de que o retorno do anfíbio sucederá. Como o menino mata o sapo durante o dia, a criada trata de queimar o animal, sem perda de tempo. A possibilidade de ter que voltar ao campo e procurar o corpo do animal é um fator que poderia piorar a situação e, até mesmo, a possibilidade de não encontrá-lo significaria seguramente a morte do menino. Essa é a associação do medo com o elemento que o potencializa, o tempo.

O ser humano não tem condições de quebrar as regras do tempo, está condicionado a adaptar-se às suas limitações. Na segunda parte do conto ocorre o contrário da primeira. É o exemplo que a criada dá à criança sobre as consequências de quem desafia um escuerzo. $\mathrm{O}$ rapaz que desafiou o sapo não acredita na advertência da mãe. Ela, por sua vez, tenta convencê-lo de todas as maneiras a buscar o corpo do animal antes que anoiteça. Quando voltam ao lugar onde o sapo foi morto este já não estava mais lá. Eles perderam tempo e por isso pagaram as consequências. O tempo era o único elemento em que podiam depositar suas esperanças. Esgotado este, nada mais puderam fazer, somente poderiam esperar o desfecho da tragédia. Qualquer tentativa de defesa seria frustrada.

\footnotetext{
${ }^{2} \mathrm{O}$ medo induzido no leitor é uma característica forte dos contos de Lovecraft, porém isso não é definitivo em todas as narrativas fantásticas, variando de acordo com a postulação de alguns teóricos.
} 
Em "El almohadón de plumas" o tempo é figurado de outra maneira. Pode-se dizer que pode ser visto desde dois pontos de vista. No conto de Lugones, tudo se passava em um único dia, a limitação estava em poucas horas do dia até à noite. Já em Quiroga, tudo se passa em vários dias, o tempo de uma doença que começa aparentemente leve e avança em um curto período até se tornar letal. O marido de Alicia tenta combater a enfermidade da esposa, chama os médicos, porém estes nada podem fazer. A doença e o tempo vencem todos. Aqui nem ciência, nem tudo o que o ser humano tenta fazer dá resultado. O tempo anunciava que Alicia definhava e sua morte estava próxima. No fim do conto o mistério é revelado: tudo se tratava do tempo de desenvolvimento de uma criatura, um parasita de ave, segundo o narrador, que cresce e se alimenta do sangue de Alicia. Nesse conto o tempo se torna imbatível por causa da ignorância da existência da criatura dentro do travesseiro. Em princípio não seria determinante como no conto de Lugones, porém é algo que Quiroga joga com o conto e o leitor, fatos da rotina de um ser humano que aparentemente podem ser simples e triviais, mas que se tornam inacessíveis diante da impotência do homem.

\section{Considerações finais}

"El escuerzo" e "El almohadón de plumas" são exemplos de textos produzidos na época auge de um tipo de literatura que buscava no mistério e no inexplicável exprimir as inquietações do ser humano, situações não justificáveis pelas leis racionais da ciência. Logo, não é raro que o racional passasse a ser questionado. O próprio Lugones, que transitou entre as ciências humanas e as exatas, o fazia porque, de certa forma, passou toda a sua vida em busca de uma resposta. Quiroga também buscou respostas para suas inquietações. A transição entre o "civilizado", como a sociedade burguesa e cultural de Buenos Aires e Paris, por exemplo, e a selva, onde habitou por longo tempo, servem como prova disso.

Os dois contistas percorreram temáticas muito próximas nessa caminhada. Nos contos referidos, o argentino se valeu de uma superstição folclórica, enquanto o uruguaio preferiu uma cena cotidiana, situações que esboçam o mesmo intento: o medo presente em nossas vidas, um sentimento com o qual ainda não aprendemos a lidar.

Na superstição do primeiro texto, um fantasma de um animal se apresenta para ceifar a vida de um rapaz, ao passo que a doença do segundo texto é causada também por um animal, um ser sórdido e vampiresco. Os dois exemplos são elementos fora do comum, sobrenaturais, imagens negativas, medos que põem à prova as crenças humanas, ansiedades de uma época em transição. 
Entretanto, podemos apontar uma diferença entre os dois contos. Enquanto em "El escuerzo" Lugones utiliza um animal real - um sapo - para desenvolver um fato irreal, Quiroga preferiu o contrário, um fato real provocado por um animal irreal - um parasita de aves irreconhecível na natureza. Há uma inversão dos valores atribuídos de acordo com a meta de cada um dos autores. Isso está associado à questão de que Lugones usou uma superstição folclórica, ou seja, uma história cuja veracidade é questionável, e que Quiroga preferiu uma cena cotidiana e real. Essa inversão, no entanto, não distancia o objetivo comum entre os contos.

Os escritos de Lugones e Quiroga refletem o pensamento que vinha sendo desenvolvido no final do século XIX e início do século XX. O fantástico apresentado em seus textos é produto das mudanças que se buscavam na época e, dessa forma, serviu como um gênero que atendia às novas exigências estéticas em que os dois rio-platenses imergiam. Assim, o fantástico em suas obras pode ser interpretado como uma mudança de tom do realismo empregado até então. Esse desvio ilustra a necessidade de modificar a tradicional forma de narrar e ver o universo, tentativa de livrar-se dos turvos e obsoletos costumes literários e artísticos. Logo, a literatura fantástica, que teve grande acolhida no Rio da Prata, propunha outros horizontes, diferentes visões sobre um mesmo elemento, a manifestação da perspectiva espiritual que prometia a modernidade.

\section{Referências}

BIOY CASARES, Adolfo. Prólogo. In: BIOY CASARES, Adolfo; BORGES, Jorge Luis; OCAMPO, Silvina. Antología de la Literatura Fantástica. Buenos Aires: Debolsillo, 2007. p. 7-14.

CORTÁZAR, Julio. Algunos aspectos del cuento. Cuadernos hispanoamericanos, Madrid, n. 255, p. 403-416, mar. 1971.

LOVECRAFT, Howard. P. [s.d]. Notas sobre el arte de escribir cuentos fantásticos. Disponível em: <http://www.ciudadseva.com/textos/teoria/opin/love01.htm>. Acesso em: 07 set 2008.

LUGONES, Leopoldo. El escuerzo. In: Cuentos fantásticos. Madrid: Editorial Castalia, 1987. p. 103-108.

OVIEDO, José Miguel. Historia de la literatura hispanoamericana 2; del Romanticismo al Modernismo. Madrid: Alianza Editorial, 2005. p. 312-322. 
QUIROGA, Horacio. Introducción. In: Cuentos. 9 ed. Madrid: Ediciones Cátedra, 2005, p. 11-101.

El almohadón de plumas. In:

Cuentos de amor, de locura y de muerte. Ciudad de México: Editores Mexicanos Unidos, 2003. p.62-65.

TODOROV, Tzvetan. Definição do Fantástico. In: 3 ed. São Paulo: Perspectiva, 2004. p. 29-46. . Introdução à literatura fantástica. 